\title{
Vorwort zur II. Auflage
}

Den Geleitworten, die ich der ro. Auflage mitgab, habe ich in den Grundsätzen nichts Neues hinzuzufügen. Daß eine jede Auflage die Fehler der vorigen, deren sie habhaft wurde, zu beseitigen strebt, ist ihre selbstverständliche Pflicht; anders verdient kein Buch ein weiterwirkendes Dasein. So geschah es auch diesmal: wo sich Mängel der äußeren Form zeigten, wo Verhaltenheit oder Leidenschaftlichkeit nicht ganz den rechten Ton getroffen hatten, griff die bessernde Hand ein. Vor allem aber ist derWechsel im Bestande der Sprachdummheiten, wie er sich auch in dem kurzen Zeitraum seit der letzten Auflage bemerkbar machte, überall berücksichtigt. Am meisten mag das im Abschnitt über "Modewörter ${ }^{4}$ hervortreten, deren Sterne, den himmlischen gleich, in ewigem Auf- und Niedergang scheinen. Endlich zeigt sich die vorliegende Auflage insofern in noch deutscherem Gewand, als sie endgültig auf alle fremdsprachlichen Fachwörter verzichtet.

Möge sie wie die vorige vielen Sprachfreunden hilfreich zur Hand sein!

Berlin-Lichterfelde, im Sommer 1943

Dir. Werner Schulze 
